\title{
Achieving Food Security in a Sustainable Development Era
}

\section{Dan Banik ${ }^{1}$}

Published online: 23 November 2019

(C) Springer Nature Switzerland AG 2019

\section{Introduction}

Despite numerous developmental successes around the world, including major strides in food production, the persistence and scale of world hunger is astonishing. According to the latest State of Food Security and Nutrition in the World report (FAO 2019), more than 820 million people suffer from daily hunger and this number has been slowly increasing in the past three years. And almost 2 billion people face some form of food insecurity - i.e. without access to safe, nutritious and sufficient food. Women, children and indigenous groups remain particularly vulnerable to hunger. In addition to undernutrition, the world is also facing the growing threat of overweight and obesity, which continue to rise fast in all world regions and is assuming epidemic proportions.

This special issue highlights the urgency of enacting strong policies that leverage the benefits of globalization while minimizing the risks in order to achieve the Sustainable Development Goals (SDGs), in particular SDG 2 related to ending hunger, improving food security and nutrition and promoting sustainable agriculture. Hunger remains a silent emergency - attracting attention mainly when large numbers die during sensational and highly visible famines. In contrast, chronic hunger continues to evade the headlines. As the world struggles to achieve better developmental outcomes in the face of climate disruption, the political, economic and social implications of this silent emergency are enormous. Hunger and food insecurity are the products of a complex set of factors, including climate related triggers (e.g. drought, flood, cyclone), which are often further exacerbated by economic hardship and conflict. Indeed, the ability of political systems to address growing food insecurity and prevent short-term and long-term food crises from escalating into famine are contingent on historical, cultural economic and political factors. Moreover, various types of inequalities - including those of income, gender, access to productive agricultural land, access to healthy and fresh food - are highly correlated with food insecurity.

Dan Banik

dan.banik@sum.uio.no

1 Centre for Development and the Environment, University of Oslo, Oslo, Norway 


\section{The 2030 Agenda and the SDGs}

With the adoption of the 2030 Agenda and its accompanying 17 SDGs by 193 heads of state in 2015 (UN 2015) - grouped under overarching themes of people, planet, dignity, prosperity, justice and partnership - sustainable development is back in the international limelight. The SDGs have been widely praised for a strong articulation of an environmental dimension, in addition to breaking new ground with goals on inequality, economic growth, energy, and peace. Many argue that despite being imperfect and highly ambitious, the SDGs are the result of a comprehensive participatory process, unparalleled in the history of global development (Doane 2016). Indeed, while its predecessor - the Millennium Development Goals (MDGs) focused exclusively on developing poor countries through foreign aid, the SDGs encompass a broader agenda, which applies to both rich and poor countries alike and is "buttressed by science and evidence" (UN 2014; UN 2015). By closely linking "sustainability" with "development" through the principles of "universality", "integration" and "leave no one behind", the 2030 Agenda has been much celebrated in academic, activist, business and policy circles as a means to stimulate a radical shift in world affairs (Banik and Miklian 2017). But the SDGs have also been criticized for their unrealistic ambitions and lack of focus. And one of the many unanswered questions relates to how low-income countries and conflict-prone fragile states will be able to plan, coordinate and finance development programs in line with the SDGs and aligned with their national interest.

There are growing concerns that many of the poorest countries will not be able to selffinance programs and that recent threats to aid from the Global North will stall efforts to advance the SDGs - thus making a stronger case for involvement of the private sector and the trillions of dollars for business opportunities that the SDGs open up (Business Commission 2017). However, operationalizing the SDGs requires a clearer understanding of the interconnected, and yet distinct, role of national governments, international agencies and businesses. This is particularly urgent in low-income countries and conflict-prone fragile states, which are confronted with the dilemmas and potential pitfalls associated with coordinating the activities of numerous competing actors. Another key issue relates to state capacity and ability of local public administrations to identify, articulate, coordinate and implement development programs aligned with the national interest, while also making it sufficiently attractive for both domestic and international actors to become involved in SDG-related activities. Governments must therefore develop the capacity to identify mere profit-making initiatives that can thwart overall social and economic development.

Despite replete with references of the "we", the 2030 Agenda does not make a clear distinction of the responsibilities of various stakeholders including national governments, international agencies and businesses (Engebretsen et al. 2017). Who will step in? And which part of the "we" will assume a greater responsibility for global development? Some argue that the pressure of achieving the 17 SDGs and their 169 targets can encourage governments to ignore the neediest. Still others point to unreliable and poor-quality data in large parts of the world and question the capacity of countries to reach "the furthest behind first" without knowing who they are (Jerven 2014; Melamed 2015). The emerging consensus has thus highlighted the importance of pursuing an integrated approach to economic, social and environmental aspects of development, requiring interdisciplinary research in addition to intersectoral collaboration and knowledge sharing. While the SDGs are not legally binding, governments are expected to take ownership and establish national frameworks for the achievement of these "global goals". Recent evidence, however, indicates slow 
implementation, and the need for greater efforts across the goals without losing focus on poverty reduction (UN 2019).

The SDGs have not thus far elicited the kind of enthusiasm among political leaders that is crucial for the success of such an ambitious agenda. In many countries, there is an on-going and often polarized national debate on the extent to which leaders should prioritise the SDGs rather than goals that are more narrowly defined to apply to local situations (e.g. prioritising allocation of resources to selected regions and targeting selected groups in the population). Most politicians are under enormous pressure to resolve current problems, challenges and deprivations and often do not typically find it politically beneficial to engage in discussions of future problems that could affect a generation that is yet to be born. Similarly, many global policy recommendations often overlook issues of local justice and messy local political realities including competition between groups for control over scarce resources. Thus, the goal of promoting sustainable development today with an eye on the wellbeing of future generations appears illusory for many governments struggling to solve current problems of extreme poverty and numerous forms of deprivation within their borders.

Even when there is ample and reliable scientific evidence pointing to the urgent need for societal transformations required to address the harmful consequences of global warming, political response in large parts of the world is lukewarm. For the SDGs to make a difference on the ground, policymakers must acquire a better understanding on the global norm of goalsetting and balance how global targets link to national and local goals. And a wide range of societal actors must hold their leaders to account for actions as well as inactions. We really must move beyond the rhetoric and the celebratory speeches to actual evidence of operationalisation and impact on the ground.

\section{Achieving SDG 2}

There is now increased attention on the staggering societal costs of hunger and the need to radically transform our local, national and international food systems into more sustainable, nutritious and efficient systems. The five essays in this special issue discuss a wide range of issues related to food systems and the ethics and politics of global and national food policies. While there has been growing attention on food insecurity in recent years, two essays draw our attention to famine, which has received far less attention. Olivier Rubin begins by distinguishing the "whispering emergency" of famine from related terms such as malnutrition and chronic hunger. He thereafter critically revisits Peter Singer's famous famine relief argument from the early 1970s, according to which we have good moral reasons for greater human engagement through charitable actions to prevent mass deaths from hunger. Rubin finds that Singer's argument, although still powerful, often appears to be disconnected from the contemporary development discourse that is more skeptical to the role of charitable benevolence in famine prevention. Although he agrees that famines ought to evoke a strong moral response, Rubin concludes that the dynamics of recent famines warrant greater attention on the obligation to criminalize famine - how individuals and groups can be more effectively held to account for the failure to prevent starvation deaths.

Alexander Vadala examines the political factors that explain the continued threat of famine in Ethiopia - a particularly interesting case given that the country is not a democracy and has a long history of famines and high levels of malnutrition. But even within Ethiopia, vulnerability to famine remains substantially high among pastoralists in the Afar region. Vadala builds on 
the Nobel laureate Amartya Sen's well-known claim that the right to freedom of expression and adversarial media reports in democracies are crucial for preventing famine. Following a critical review of Sen's entitlement approach, he unpacks the close linkages between food insecurity and pastoralism in Ethiopia. Vadala finds that a set of policy decisions exacerbated pastoral vulnerability, including the closure of the Ethiopia-Eritrea border and the ban on salt trade with Djibouti. The recent initiatives undertaken by the new Ethiopian government under Abiy Ahmed offers some hope, but achieving SDG2 requires that the authorities respect the rights, needs and demands of vulnerable groups.

Jessica Fanzo focuses on why increased attention on healthy and sustainable diets is crucial for achieving SDG2. Although there has been a growing international discourse on what constitutes a "healthy diet", improving the dietary habits of the world's population has been extremely challenging. Most countries face some form of malnutrition, and sub-optimal diets are a major cause of various forms of hunger. Fanzo discusses the crucial role of SDG2 in achieving the wider 2030 Agenda for sustainable development and examines the uneven global progress thus far, including potential challenges ahead. She also critically discusses the impact of numerous ethical considerations and inherent trade-offs related to the achievement of sustainable and healthy diets, including the rapid population growth, economic crises, income inequality and climate change.

Although the SDGs are receiving increased international attention, Marc Cohen finds that the global agenda aimed at reducing hunger is characterized by serious policy incoherence. The international discourse is frequently characterized by fancy rhetoric and generous sounding pledges that have not resulted in greater political commitments to ending hunger. While national policies and budgets continue to neglect agriculture and irrigation, the agriculture trade and security policies of influential foreign donor countries also often undercut efforts to strengthen agricultural development in low-income country contexts. Cohen examines the growing gap between words and actions. He concludes that policy incoherence on SDG 2 results from a combination of agricultural subsidies in high-income countries and the resulting dumping of surplus products in aid-recipient countries, an excessive focus on defense spending and arms trade in many parts of the world and ineffective policies aimed at supporting smallholder farmers.

My essay with Michael Chasukwa focuses on the politics of food policy in Malawi - one of the poorest countries in the world. Many low-income countries, including those that are heavily dependent on foreign aid - are struggling to formulate and implement policies aimed at promoting the SDGs. Although Malawi has achieved some success in relation to reducing child mortality and combating HIV/AIDs, food insecurity remains high despite considerable political talk on the need to strengthen the country's agriculture sector. We focus on a key intervention of the Malawian government in recent years - the Farm Input Subsidy program (FISP) - which is characterized by institutional rivalry, lack of coordination, inadequate financial resources, corruption and poor implementation. Agriculture policy in the country is not only haphazardly formulated and implemented, it is also excessive focused on securing availability of maize at the expense of other crops with the potential of diversifying diets and promoting greater food security.

The five essays in this special issue collectively identify and discuss barriers and challenges to achieving the SDGs in general and SDG 2 in particular. The overall conclusion in recent reports on hunger and food insecurity is that the world is continuing to move further away from achieving SDG 2. And the UN Special Rapporteur on Extreme Poverty and Human Rights (Human Rights Council 2019) has recently argued that if the current trend of global 
warming continues, several hundred million people risk food insecurity with a decline in food production due to crop yield losses. These groups also risk water insecurity and greater risks of malaria, diarrhea and heat stress. An increase in the frequency of droughts and floods and the resulting displacement will have a disproportionate impact on the daily lives of those living in poverty. The enormous scale of world hunger requires us to update our approaches (making them bolder and involving multisectoral collaboration across different policy domains) and ensure that our interventions are better targeted both socially and geographically, taking into account inequality, conflict, gender, climate and economic slowdowns.

\section{References}

Banik, D. and Miklian, J. (2017) "New Business: The Private Sector as a New Global Development Player", Global Policy, https://www.globalpolicyjournal.com/blog/24/11/2017/new-business-private-sector-newglobal-development-player

Business Commission (2017) Better Business Better World, http://report.businesscommission. org/uploads/BetterBiz-BetterWorld_170215_012417.pdf

Doane, D. (2016) "We Won't Conquer the Mountains of the SDGs Without Humility", The Guardian, https://www.theguardian.com/global-development-professionals-network/2016/jul/07/sdgs-progress-stayhumble. Accessed 20 Nov 2019

Engebretsen, E., Heggen, K., Banik, D. \& Ottersen, O. P. (2017) “The 2030 Agenda for Sustainable Development and the Power of Ambiguities", https://www.whatworks.uio.no/blog/2018/sdg_ responsibility.html

FAO (2019) State of Food Security and Nutrition in the World, http:/www.fao.org/3/ca5162en/ca5162en.pdf. Accessed 20 Nov 2019

Human Rights Council (2019) Climate Change and Poverty,https://www.ohchr. org/Documents/Issues/Poverty/A_HRC_41_39.pdf

Jerven, M. (2014) "Benefits and Costs of the Data for Development Targets for the Post-2015 Development Agenda", Copenhagen Consensus Center, https://www.copenhagenconsensus.com/sites/default/files/data assessment__ jerven.pdf

Melamed, C. (2015) "Leaving No One Behind: How the SDGs can Bring About Real Change", Briefing paper, Overseas Development Institute, https://www.odi.org/sites/odi.org.uk/files/odi-assets/publications-opinionfiles/9534.pdf

UN (2014) The Road to Dignity by 2030: Ending Poverty, Transforming All Lives and Protecting the Planet, https://www.un.org/disabilities/documents/reports/SG_Synthesis_Report_Road_to_Dignity_by_2030.pdf

UN (2015) Transforming Our World: The 2030 Agenda for Sustainable Development, https://sustainabledevelopment.un.org/post2015/transformingourworld . Accessed 20 Nov 2019

UN (2019) The Sustainable Development Goals Report 2019, https://unstats.un.org/sdgs/report/2019/TheSustainable-Development-Goals-Report-2019.pdf

Publisher's Note Springer Nature remains neutral with regard to jurisdictional claims in published maps and institutional affiliations. 